Chronic Obstructive Pulmonary Diseases: Journal of the COPD Foundation

\author{
Original Research
}

\title{
Risk Factors for Venous Thromboembolism in Chronic Obstructive Pulmonary Disease
}

Victor Kim, MD, ${ }^{1}$ Nishant Goel, MD, ${ }^{1}$ Jinal Gangar, MBBS, MPH, ${ }^{1}$ Huaqing Zhao, PhD, ${ }^{1}$ David E. Ciccolella, $\mathrm{MD},{ }^{1}$ Edwin K. Silverman, MD, PhD, ${ }^{2}$ James D. Crapo, MD, ${ }^{3}$ Gerard J. Criner, $\mathrm{MD}^{1}$ and the COPDGene Investigators

\section{Abstract}

Background: COPD patients are at increased risk for venous thromboembolism (VTE). VTE however remains under-diagnosed in this population and the clinical profile of VTE in COPD is unclear.

Methods: Global initiative for chronic Obstructive Lung Disease (GOLD) stages II-IV participants in the COPD Genetic Epidemiology (COPDGene) study were divided into 2 groups: VTE+, those who reported a history of VTE by questionnaire, and VTE-, those who did not. We compared variables in these 2 groups with either t-test or chisquared test for continuous and categorical variables, respectively. We performed a univariate logistic regression for VTE, and then a multivariate logistic regression using the significant predictors of interest in the univariate analysis to ascertain the determinants of VTE.

Results: The VTE+ group was older, more likely to be Caucasian, had a higher body mass index (BMI), smoking history, used oxygen, had a lower 6-minute walk distance, worse quality of life scores, and more dyspnea and respiratory exacerbations than the VTE- group. Lung function was not different between groups. A greater percentage of the VTE+ group described multiple medical comorbidities. On multivariate analysis, BMI, 6-minute walk distance, pneumothorax, peripheral vascular disease, and congestive heart failure significantly increased the odds for VTE by history.

Conclusions: BMI, exercise capacity, and medical comorbidities were significantly associated with VTE in moderate to severe COPD. Clinicians should suspect VTE in patients who present with dyspnea and should consider possibilities other than infection as causes of COPD exacerbation.

\footnotetext{
Abbreviations: National Heart Lung and Blood Institute, NHLBI; venous thromboembolism, VTE; Global initiative for chronic Obstructive Lung Disease, GOLD; participants who reported a history of VTE, VTE+; participants who did not report a history of VTE, VTE-; COPD Genetic Epidemiology study, COPDGene; body mass index, BMI; pulmonary embolism, PE; computed tomography, CT; internal review board, IRB; modified Medical Research Council dyspnea scale, mMRC; St. George's Respiratory Questionaire, SGRQ; Short Form (36) Health Survey, SF-36; physical component scores, PCS; mental component scores, MCS; congestive heart failure, CHF; diabetes mellitus, DM; hypertension, HTN; peripheral vascular disease, PVD; stroke, CVA; transient ischemic attacks, TIA; coronary artery disease, CAD; myocardial infarction, MI; pneumothorax, PTX; gatroesophageal reflux, GERD; peptic ulcer disease, PUD; osteoporosis, osteo; osteoarthritis, OA; hypercholesterolemia, chol; odds ratio, OR; confidence interval, CI; Registro Informatizado de la Enfermedad Tromboembolica, RIETE Funding Support: This study was supported by the National Heart Lung and Blood Institute (NHLBI) R01 HL089856 and R01 HL089897 Date of Acceptance: July 24, 2014

Citation: Kim V, Goel N, Gangar J, et al; and the COPDGene Investigators. Risk factors for venous thromboembolism in chronic obstructive pulmonary disease. J COPD F. 2014; 1(2): 239-249. doi: http://dx.doi.org/10.15326/jcopdf.1.2.2014.0133
}

1 Section of Pulmonary and Critical Care Medicine, Department of Medicine, Temple University School of Medicine, Philadelphia, Pennsylvania
2 Division of Pulmonary and Critical Care Medicine and Channing Division of Network Medicine, Brigham and Women's Hospital, Harvard Medical School, Boston, Massachusetts

3 Division of Pulmonary, Critical Care and Sleep Medicine, National Jewish Health, University of Colorado, School of Medicine, Denver 


\section{Address correspondence to:}

Victor Kim, MD

785 Parkinson Pavilion

3401 North Broad Street

Philadelphia, PA 19140

(215) 707-5864 (office)

(215) 707-6867 (fax)

Victor.kim@tuhs.temple.edu

\section{Keywords:}

COPD; venous thromboembolism; VTE; peripheral vascular disease; PVD; pulmonary embolism

\section{Introduction}

Chronic obstructive pulmonary disease (COPD) is a leading cause of morbidity and mortality worldwide. It is characterized by systemic inflammation resulting in comorbidities such as coronary artery disease, osteoporosis, and musculoskeletal dysfunction. COPD patients are thought at increased risk for venous thromboembolism (VTE) because of immobilization, heightened systemic inflammation, cigarette smoking, and venous stasis. ${ }^{1}$ VTE however, remains underdiagnosed in this patient population because its symptoms mimic a COPD exacerbation. Postmortem studies in COPD have found pulmonary embolism (PE) in $28 \%-51 \%$ of cases. ${ }^{2,3}$ One study found PE diagnosed by computed tomography (CT) angiography in $25 \%$ of individuals presenting with an unknown etiology for a COPD exacerbation. ${ }^{4}$ Overall, the reported prevalence of VTE during COPD exacerbations ranges from 5\%-29\%. ${ }^{5-8}$

Prior literature on the diagnosis of VTE in COPD provides little description of the associated clinical characteristics. To complicate matters, VTE in COPD has prognostic importance. One study found significantly higher 1-year mortality in COPD exacerbation with VTE (61.9\% vs. $31.8 \%$, p=0.013). ${ }^{9}$ Another showed increased duration of hospitalization and need for mechanical ventilation. ${ }^{5}$ Based on current data, it is unclear what COPD risk factors or clinical characteristics places patients at increased VTE risk. We performed an epidemiological analysis of the COPD Genetic Epidemiology (COPDGene) study in an effort to characterize COPD individuals with a history of VTE. We hypothesized that individuals with a history of VTE would be more hypoxemic, have more comorbidities, a lower exercise capacity, and a greater history of respiratory exacerbations.

\section{Methods}

The COPDGene Study is multicenter cross-sectional study investigating the genetic epidemiology of COPD; it has enrolled $>10,000$ participants in 21 clinical centers. Each site obtained internal review board (IRB) approval prior to participant recruitment. The study protocol has been previously described in depth. ${ }^{10}$ Briefly, inclusion criteria include non-Hispanic whites or African Americans ages 45-80 years, never smokers (control participants) or smokers with $>10$ pack year history. Major exclusion criteria include a history of other lung disease except asthma, pregnancy, surgical lung resection of at least one lobe, lung cancer, active cancer under treatment, or COPD exacerbation $<1$ month prior to enrollment.

All participants underwent clinical characterization, spirometry, 6-minute walk test, and chest computed tomography (CT). Participants completed standardized questionnaires to assess respiratory symptoms, quality of life measures, and past medical history. Exacerbations were defined as an increase in symptoms requiring treatment with steroids or antibiotics, and severe exacerbations were defined as exacerbations that required an emergency department visit or hospitalization. In addition to multiple comorbidities, participants were asked if they ever had been diagnosed with a blood clot in their legs or lungs. The participants were divided into 2 groups, VTE+, those who answered yes, and VTE-, those who answered no. Participants who did not respond were placed in the VTE- group. Based on Global initiative for chronic Obstructive Lung Disease (GOLD) criteria, participants were grouped as non-smoking controls ( $\mathrm{n}=108)$; GOLD Unclassified (GOLDU), 0, and stage I ( $\mathrm{n}=6439$ ); and GOLD stages II-IV ( $\mathrm{n}=3690)$. GOLD U participants demonstrated a reduced forced expiratory volume in 1 second $\left(\mathrm{FEV}_{1}\right)$ in the presence of an $\mathrm{FEV}_{1}$ /forced vital capacity (FVC) ratio $\geq 0.7$. A detailed analysis of the GOLD stage II-IV participants was performed because this group is most symptomatic and prone to COPD exacerbations.

\section{Statistical Analysis}

All analyses were performed using SPSS v21.0. Independent t-tests and chi-square tests were done to assess differences between the VTE+ and VTEgroups. Univariate analyses were performed using binomial logistic regression to calculate odds ratios for the presence of VTE with each variable. Multivariate 
logistic regression with backwards stepwise elimination was done with the significant covariates identified during univariate analysis. Data are presented as mean $\pm S D$ unless stated otherwise. A p value of $<0.05$ was considered statistically significant.

\section{Results}

A total of 10,237 participants were analyzed (63 individuals were excluded because of missing data). A history of VTE was noted in 435 participants (4.25\%). The prevalence of VTE in GOLD stage II-IV was higher compared to nonsmoking controls and the GOLD U, $O$ and stage I participants $(5.7 \%$ vs. $3.7 \%$ vs. $3.4 \%$ respectively, $\mathrm{p}<0.0001)$. Baseline characteristics of the 3690 GOLD stage II-IV participants analyzed are summarized in Table 1. VTE+ participants were older (66.4 \pm 8.4 vs. $63.2 \pm 8.5$ years, $\mathrm{p}<0.0001)$, had a higher body mass index (BMI) (29.2 \pm 7.3 vs. $28.0 \pm 6.2$ $\left.\mathrm{kg} / \mathrm{m}^{2}, \mathrm{p}=0.005\right)$, had a greater smoking history $(58.2 \pm 36.4$ vs. $52.7 \pm 26.9$ pack years, $\mathrm{p}=0.0048$ ), were less likely to be current smokers (26.7 vs. $41.5 \%, \mathrm{p}<0.0001$ ), and were more likely to be non-Hispanic whites (84.3 vs. $76.9 \%, \mathrm{p}=0.01$ ) than VTE- participants.

Resting heart rate, lung function, percent emphysema, and total lung capacity were not different between groups. VTE+ participants had a lower mean resting oxygen saturation $(93.9 \pm 4.1$ vs. $94.8 \pm 3.5 \%, \quad p=0.001)$ and a shorter 6-minute walk distance compared to VTE- participants ( $1047 \pm 425$ vs. $1182 \pm 394$ feet, $p<0.0001)$. Total exacerbation frequency was greater in the VTE+ group ( $1.03 \pm 1.49$ vs. $0.73 \pm 1.23$ exacerbations/ patient/year, $p<0.0001)$, and the prevalence of severe exacerbations was higher in VTE+ participants (30.5 vs. $22.2 \%, \mathrm{p}=0.0006$ ). Moreover, the VTE+ group had higher modified Medical Research Council (mMRC)

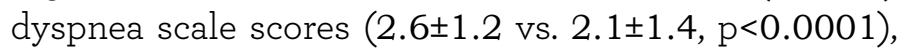
higher St. George's Respiratory Questionaire (SGRQ)

\section{Table 1. Patient Characteristics of GOLD Stage II-IV Participants}

\begin{tabular}{|c|c|c|c|c|}
\hline & $\begin{array}{c}\text { VTE- } \\
(n=3479)\end{array}$ & $\begin{array}{c}\text { VTE+ } \\
(n=210)\end{array}$ & $\begin{array}{c}\text { Total } \\
(\mathrm{n}=3690)\end{array}$ & $p$ \\
\hline Age (years) & $63.19+8.50$ & $66.39+8.38$ & $63.38+8.53$ & $<0.0001$ \\
\hline Gender (\% male, $[n])$ & $55.9(1945)$ & $50.5(106)$ & $55.6(2051)$ & 0.12 \\
\hline Race (\%Caucasian $[n])$ & $76.9(2676)$ & $84.3(177)$ & $77.3(2853)$ & 0.01 \\
\hline Body Mass Index $\left(\mathrm{kg} / \mathrm{m}^{2}\right)$ & $27.98+6.20$ & $29.24+7.31$ & $28.05+6.28$ & 0.0047 \\
\hline Current Smoking (\%) & 41.5 & 26.7 & 40.7 & $<0.0001$ \\
\hline Smoking History (pack years) & $52.68+26.89$ & $58.21+36.40$ & $53.00+27.54$ & 0.0048 \\
\hline Oxygen Use \%(n) & $27.2(946)$ & $41.4(87)$ & $28(1033)$ & $<0.0001$ \\
\hline Heart Rate (beats/min) & $77.56+13.16$ & $77.01+13.40$ & $77.52+13.17$ & 0.560 \\
\hline Resting Oxygen Saturation (\%) & $94.75+3.52$ & $93.90+4.05$ & $94.70+3.56$ & 0.001 \\
\hline 6-Minute Walk Distance (feet) & $1182.15+394.22$ & $1047.39+425.10$ & $1174.82+397.08$ & $<0.0001$ \\
\hline BODE Index & $2.92+2.05$ & $3.21+2.08$ & $2.94+2.05$ & 0.059 \\
\hline $\mathrm{FEV}_{1} \%$ Predicted & $50.21+17.99$ & $50.43+17.74$ & $50.23+17.97$ & 0.860 \\
\hline FVC \%Predicted & $76.42 \pm 17.31$ & $75.10 \pm 16.29$ & $76.38 \pm 17.25$ & 0.515 \\
\hline $\mathrm{FEV}_{1} / \mathrm{FVC}$ & $0.49+0.13$ & $0.50+0.14$ & $0.50+0.13$ & 0.390 \\
\hline Percent Emphysema & $14.97+13.39$ & $15.24+12.73$ & $14.98+13.35$ & 0.820 \\
\hline TLC (L) & $6.11+1.45$ & $5.88+1.42$ & $6.10+1.46$ & 0.100 \\
\hline mMRC Dyspnea Score & $2.11+1.42$ & $2.57+1.24$ & $2.14+1.41$ & $<0.0001$ \\
\hline SF-36 PCS & $38.99+10.51$ & $34.63+10.50$ & $38.71+10.56$ & $<0.0001$ \\
\hline SF-36 MCS & $48.37+12.71$ & $47.72+13.38$ & $48.33+12.75$ & 0.610 \\
\hline SGRQ Symptoms & $45.83+25.05$ & $49.41+24.48$ & $46.04+25.03$ & 0.044 \\
\hline SGRQ Activity & $56.82+27.35$ & $64.24+25.29$ & $57.25+27.29$ & 0.0001 \\
\hline SGRQ Impact & $29.78+21.59$ & $33.89+21.41$ & $30.01+21.60$ & 0.007 \\
\hline SGRQ Total & $40.61+21.91$ & $45.68+20.95$ & $40.90+21.88$ & 0.001 \\
\hline Exacerbations per Year (no./pt) & $0.73+1.23$ & $1.03+1.49$ & $0.75+1.25$ & 0.001 \\
\hline Severe Exacerbations (\%, $[n]$ ) & $22.2(773)$ & $30.5(64)$ & $22.7(837)$ & 0.006 \\
\hline
\end{tabular}

Values expressed as mean \pm SD unless stated otherwise. P values represent differences between VTE+ and VTE- groups

FEV1 = forced expiratory volume in 1 second, FVC = forced vital capacity, TLC = total lung capacity (calculated from inspiratory CT scan), $\mathrm{mMRC}=$ modified Medical Research Council dyspnea scale, SF-36 = short form 36; PCS = physical component score; MCS = mental component score;

$\mathrm{SGRQ}=$ St. George's Respiratory Questionnaire 


\section{Figure 1. Health-Related Quality of Life}

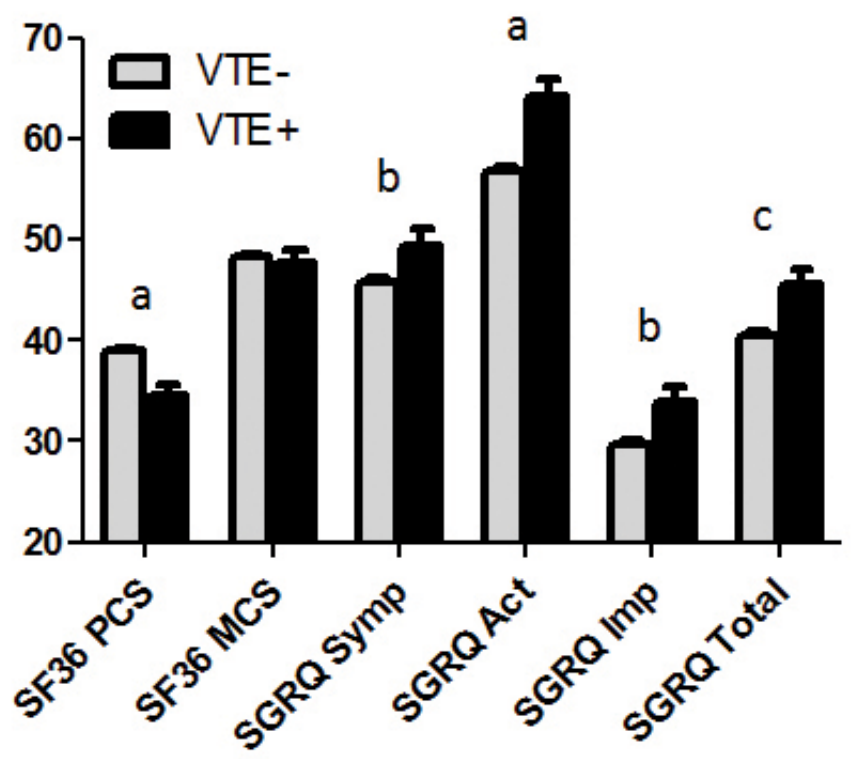

Health-related quality of life as measured by the Short Form-36 and St. George's Respiratory Questionnaire and their components. Data presented as mean $\pm S E$. PCS = physical component score. MCS = mental component score, Symp = symptom score, Act = activity score, $\operatorname{Imp}=$ impact score. $a=p \leq 0.0001, b=p<0.05, c=p=0.0011$.

\section{Figure 2. Percentage of Participants Reporting Selected Comorbidities}

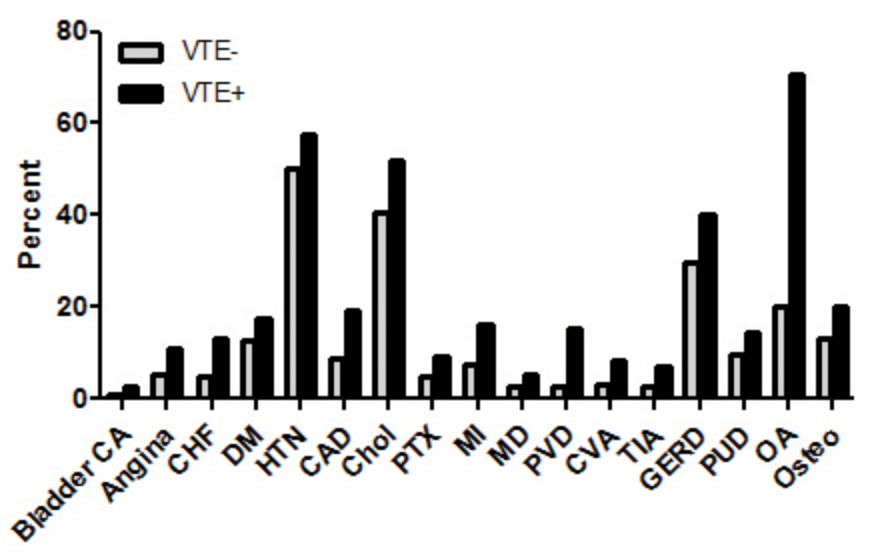

Differences in comorbidities between groups are all statistically significant $(p<0.05)$.

$\mathrm{DM}=$ diabetes mellitus, $\mathrm{HTN}=$ hypertension, $\mathrm{Chol}=$ hypercholesterolemia, $\mathrm{MD}=$ macular degeneration, $\mathrm{PVD}$ $=$ peripheral vascular disease, TIA $=$ transient ischemic attack, $\mathrm{CHF}=$ congestive heart failure, $\mathrm{CVA}=$ stroke, GERD = gastroesophageal reflux, PUD = peptic ulcer disease, $\mathrm{OA}=$ osteoarthritis, Osteo = osteoporosis, CAD = coronary artery disease, $\mathrm{MI}=$ myocardial infarction, $\mathrm{Chol}=$ hypercholesterolemia, PTX = pneumothorax

\section{Table 2. Comorbidities Stratified by History of VTE in GOLD Stage II-IV Participants}

\begin{tabular}{|c|c|c|c|c|c|}
\hline & \multicolumn{2}{|c|}{ VTE- $(n=3479)$} & \multicolumn{2}{|c|}{ VTE+ $(n=210)$} & \multirow[t]{2}{*}{$p$} \\
\hline & $n$ & $\%$ & $n$ & $\%$ & \\
\hline Bladder Cancer & 30 & 0.9 & 5 & 2.4 & 0.028 \\
\hline Breast Cancer & 75 & 2.2 & 7 & 3.3 & 0.261 \\
\hline Colon Cancer & 30 & 0.9 & 2 & 1.0 & 0.891 \\
\hline Prostate Cancer & 103 & 3.0 & 10 & 4.8 & 0.142 \\
\hline Angina & 177 & 5.1 & 23 & 11.0 & $<0.0001$ \\
\hline Congestive Heart Failure & 170 & 4.9 & 28 & 13.3 & $<0.0001$ \\
\hline Diabetes & 445 & 12.8 & 37 & 17.6 & $<0.0001$ \\
\hline High Blood Pressure & 1747 & 50.2 & 121 & 57.6 & 0.044 \\
\hline Coronary Artery Disease & 301 & 8.7 & 40 & 19.0 & 0.038 \\
\hline Hypercholesterolemia & 1419 & 40.8 & 109 & 51.9 & 0.001 \\
\hline Myocardial Infarction & 263 & 7.6 & 34 & 16.2 & $<0.0001$ \\
\hline Peripheral Vascular Disease & 94 & 2.7 & 32 & 15.2 & $<0.0001$ \\
\hline Stroke & 115 & 3.3 & 17 & 8.1 & $<0.0001$ \\
\hline Transient Ischemic Attack & 97 & 2.8 & 15 & 7.1 & $<0.0001$ \\
\hline Macular Degeneration & 95 & 2.7 & 11 & 5.2 & 0.035 \\
\hline Pneumothorax & 164 & 4.7 & 19 & 9.0 & 0.005 \\
\hline Gastroesophageal Reflux & 1032 & 29.7 & 84 & 40.0 & 0.002 \\
\hline PepticUlcer Disease & 342 & 9.8 & 30 & 14.3 & 0.037 \\
\hline Compression Fractures & 211 & 6.1 & 19 & 9.0 & 0.083 \\
\hline Hip Fracture & 83 & 2.4 & 7 & 3.3 & 0.387 \\
\hline Osteoarthritis & 701 & 20.1 & 148 & 70.5 & 0.001 \\
\hline Osteoporosis & 454 & 13.0 & 42 & 20.0 & 0.004 \\
\hline Rheumatoid Arthritis & 301 & 8.7 & 24 & 11.4 & 0.169 \\
\hline
\end{tabular}

total scores ( $45.7 \pm 21.0$ vs. $40.6 \pm 21.9, \mathrm{p}=0.0011)$ and lower Short Form (36) Health Survey (SF-36) physical component

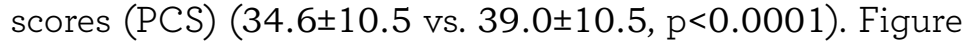
1 graphically displays differences in health-related quality of life between the 2 groups.

There were significant differences in comorbidities between the 2 groups. Histories of bladder cancer, congestive heart failure diabetes hypertension, peripheral vascular disease, stroke, transient ischemic attacks, angina, coronary artery disease, myocardial infarction, pneumothorax, macular degeneration, gastroesophageal reflux, peptic ulcer disease, osteoporosis, osteoarthritis, and hypercholesterolemia were higher in VTE+ participants (data summarized in Table 2). Figure 2 displays the significantly different comorbidities in the VTE+ and VTE- groups. 
Univariate logistic regression for multiple clinical variables and the presence of VTE is summarized in Table 3. The odds ratio (OR) of having a history of VTE was 1.043 (95\% confidence interval [CI] 1.025, 1.062; p<0.001) with every 50-foot decrease walked during the 6-minute walk test. Each additional exacerbation in the year prior to enrollment resulted in $17 \%$ increased likelihood of having a VTE (OR 1.171; 95\% CI 1.068, 1.285; $\mathrm{p}=0.001)$. The strongest risk factors for VTE were peripheral vascular disease (OR 6.474, 95\% CI 4.218, 9.9237, $\mathrm{p}<0.0001)$, followed by congestive heart failure (OR 2.995, 95\% CI 1.954, 4.588, $\mathrm{p}=0.001)$, bladder cancer (OR 2.804, 95\% CI 1.077, 7.303, $\mathrm{p}=0.035)$, transient ischemic attacks (OR 2.681, 95\% CI 1.528, 4.706, $\mathrm{p}=0.001)$, and stroke (OR 2.577, 95\% CI 1.517, 4.376, $\mathrm{p}<0.0001)$. Current smoking posed a decreased risk of VTE (OR 0.512, 95\% CI 0.375, $0.701, \mathrm{p}<0.0001)$.

Multivariate logistic regression using the variables found to be statistically significant in univariate analysis with backward stepwise elimination is summarized in Figure 3. The covariates that remained significant included congestive heart failure (OR 2.048, 95\% CI 1.052, 3.984), peripheral vascular disease (OR 4.287, 95\% CI 2.177, 8.442), BMI (OR 1.037 per $\mathrm{kg} / \mathrm{m}^{2}, 95 \%$ CI $\left.1.006,1.068\right)$, 6-minute walk distance (OR 1.036 per 50-foot decrease, 95\% CI $1.009,1.064)$, and pneumothorax (OR 2.981, 95\% CI 1.474, 6.029). Gastroesophageal reflux and myocardial infarction conferred a nearly statistically significant increased association for VTE (OR

\section{Table 3. Univariate Logistic Regression for the Presence of Venous Thromboembolism}

\begin{tabular}{|c|c|c|c|c|}
\hline & OR & $95^{\circ}$ & C.I. & Sig. \\
\hline Age (per year) & 1.047 & 1.029, & 1.065 & $<0.0001$ \\
\hline Race (African American) & 0.621 & 0.425 & 0.908 & 0.014 \\
\hline Gender (female) & 1.244 & 0.941 & 1.644 & 0.125 \\
\hline Current Smoking & 0.512 & 0.375 & 0.701 & $<0.0001$ \\
\hline Smoking History (pack years) & 1.006 & 1.002 & 1.011 & 0.005 \\
\hline 6-min Walk Distance (per 50ft dec) & 1.043 & 1.025, & 1.062 & $<0.0001$ \\
\hline Resting $\mathrm{SaO}_{2}$ & 0.944 & 0.912 & 0.976 & 0.001 \\
\hline BMI $\left(\mathrm{kg} / \mathrm{m}^{2}\right)$ & 1.031 & 1.009 & 1.052 & 0.005 \\
\hline Oxygen Use & 1.353 & 0.846 & 2.164 & 0.207 \\
\hline SGRQ, Total & 1.011 & 1.004 & 1.017 & 0.001 \\
\hline SF36 PCS Score & 0.961 & 0.943 & 0.979 & $<0.0001$ \\
\hline MMRC Dyspnea Score & 1.274 & 1.146, & 1.417 & $<0.0001$ \\
\hline History of Severe Exacerbations & 1.535 & 1.132 & 2.081 & 0.006 \\
\hline Exacerbation Frequency (no./pt/yr) & 1.171 & 1.068 & 1.285 & 0.001 \\
\hline Angina & 2.295 & 1.450 & 3.630 & $<0.0001$ \\
\hline Congestive Heart Failure & 2.995 & 1.954 & 4.588 & $<0.0001$ \\
\hline CoronaryArtery Disease & 2.484 & 1.726 , & 3.576 & $<0.0001$ \\
\hline Peripheral Vascular Disease & 6.474 & 4.218 & 9.937 & $<0.0001$ \\
\hline Stroke & 2.577 & 1.517 & 4.376 & $<0.0001$ \\
\hline Transient Ischemic Attack & 2.681 & 1.528 & 4.706 & 0.001 \\
\hline Hypertension & 1.347 & 1.016 & 1.785 & 0.038 \\
\hline Hypercholesterolemia & 1.567 & 1.185 , & 2.071 & 0.002 \\
\hline Myocardial Infarction & 2.362 & 1.602 & 3.482 & $<0.0001$ \\
\hline Diabetes & 1.458 & 1.009 & 2.108 & 0.045 \\
\hline Bladder Cancer & 2.804 & 1.077 & 7.303 & 0.035 \\
\hline Breast Cancer & 1.565 & 0.712 & 3.440 & 0.265 \\
\hline Colon Cancer & 1.105 & 0.262 & 4.657 & 0.891 \\
\hline Prostate Cancer & 1.638 & 0.843 & 3.185 & 0.145 \\
\hline Macular Degeneration & 1.969 & 1.038 & 3.736 & 0.038 \\
\hline Gastroesophageal Reflux & 1.581 & 1.188 & 2.103 & 0.002 \\
\hline Peptic Ulcer Disease & 1.528 & 1.022 & 2.285 & 0.039 \\
\hline Compression Fractures & 1.541 & 0.942 & 2.519 & 0.085 \\
\hline Hip Fracture & 1.411 & 0.644 & 3.091 & 0.390 \\
\hline Osteoarthritis & 1.660 & 1.220 & 2.258 & 0.001 \\
\hline Osteoporosis & 1.665 & 1.171 & 2.368 & 0.005 \\
\hline Rheumatoid Arthritis & 1.362 & 0.876 & 2.117 & 0.170 \\
\hline Pneumothorax & 2.011 & 1.223, & 3.305 & 0.006 \\
\hline
\end{tabular}




\section{Figure 3. Multivariate Model for the Presence of Venous Thromboembolism}

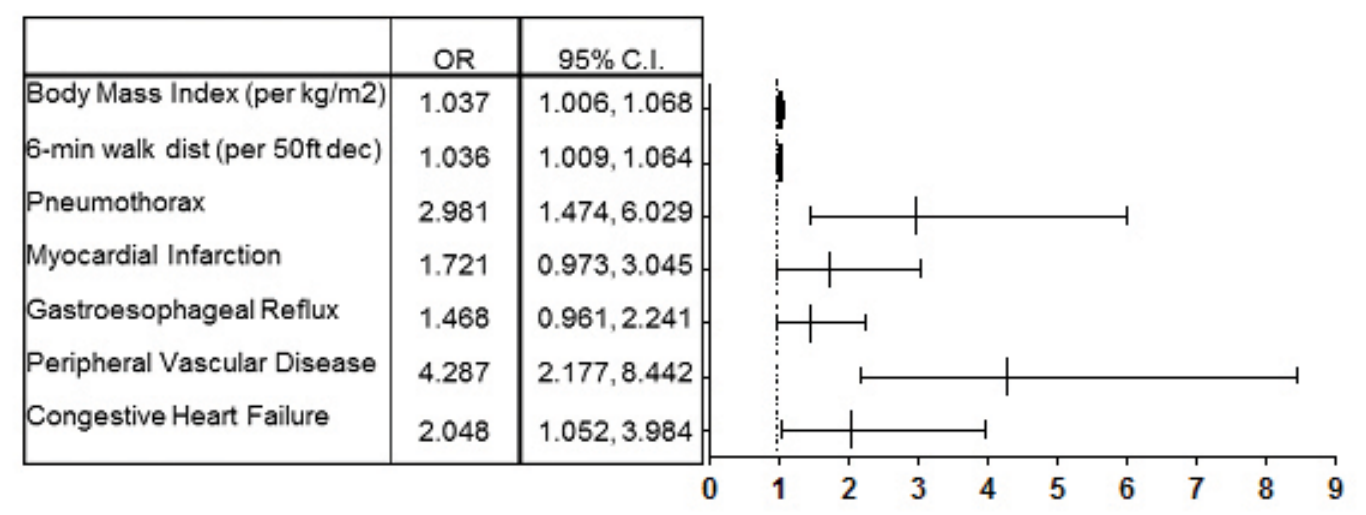

a population-based study of 2488 patients with VTE, $19.5 \%$ had a history of COPD. ${ }^{11}$ The COPD patients were older (mean age 68 vs. 63 years), and had a higher frequency of heart failure $(35.5 \%$ vs. $12.9 \%)$, and immobility $(53.5 \%$ vs. $43.3 \%$, all $\mathrm{p}<0.0001)$ compared to those without COPD. The COPD individuals were more likely to die in the hospital and within 30
$1.468,95 \%$ CI $0.961,2.241$ and OR $1.721,95 \%$ CI $0.973,3.045$, respectively).

\section{Discussion}

The major findings of this retrospective cross-sectional analysis are the following: smokers with worse airflow obstruction were more likely to have a history of VTE compared to nonsmoking controls and smokers with no or mild airflow obstruction; a lower 6-minute walk distance, worse quality of life, increased exacerbation frequency, and greater amount of oxygen use were associated with a history of VTE in a large cohort of unselected COPD individuals; and those with a history of VTE were older, heavier, had a greater smoking history, and were more likely to have numerous medical comorbidities. Furthermore, we found that the primary associations with VTE in GOLD stage II-IV participants were BMI, 6-minute walk distance, history of pneumothorax, congestive heart failure, and peripheral vascular disease. These effects were independent of the degree of airflow obstruction. To our knowledge, this is the first study of significant size that has comprehensively characterized the associated factors and medical profiles of COPD individuals with VTE.

The literature supporting the association of COPD and VTE continues to grow. Tillebrand et al found that in $25 \%$ of 211 patients with severe COPD exacerbations without an identifiable cause, the exacerbations were actually related to PEs. ${ }^{4}$ VTE has also been associated with COPD exacerbations with identifiable triggers, accounting for up to $16 \%$ of hospitalized patients with COPD exacerbations. ${ }^{9}$ Another study found the incidence of PE in COPD exacerbations to be $29 \% .^{8}$ In days of the VTE diagnosis. The Registro Informatizado de la Enfermedad Tromboembolica (RIETE) registry reported that $14 \%$ of patients with confirmed $\mathrm{PE}$ also had COPD. ${ }^{12}$ In contrast, a recent study reported a low incidence of $\mathrm{PE}$ in patients hospitalized for acute exacerbation of COPD: $6.2 \%$ of patients with a clinical suspicion of $\mathrm{PE}$, and only $1.3 \%$ of those with low suspicion. ${ }^{13}$ A meta-analysis found that the prevalence of PE in acute exacerbations of COPD was $19.9 \%{ }^{14}$ Our study identified a small cohort of participants (5.7\%) with VTE, which is consistent with some studies with similar prevalence rates. ${ }^{5,15,16}$ It should be noted that most studies have examined the prevalence of VTE in the setting of an acute exacerbation, but our cohort reported history of VTE irrespective of exacerbations.

The association between arterial vascular disease and cardiovascular risk factors with venous thrombosis has been described extensively. Prandoni et al found that the odds ratios for carotid plaques by ultrasonography in individuals with spontaneous venous thrombosis were 1.8 compared to control participants and 2.3 compared to those with a provoked venous thrombosis (i.e. postpartum, history of cancer, recent leg fracture and immobilization). ${ }^{17}$ More recently, lower levels of high density lipoprotein cholesterol and higher levels of low density lipoprotein cholesterol were found in men with VTE compared to controls. ${ }^{18}$ A metaanalysis of cardiovascular risk factors and VTE found that hypertension and obesity conferred increased risk for VTE compared to controls (OR 1.51 and 2.33, respectively). ${ }^{19}$ A 20 -year population-based cohort study found that in over 16,000 participants, individuals diagnosed with $\mathrm{PE}$ had a relative risk of 2.60 and 2.93 for myocardial infarction and stroke, 
respectively, in the following year. ${ }^{20}$ Indeed, we found that participants with a history of VTE had greater histories of angina, diabetes, hypertension, coronary artery disease, hypercholesterolemia, myocardial infarction, stroke, transient ischemic attack, and peripheral vascular disease in univariate analysis, which supports prior studies linking the association between atherosclerosis and VTE. Peripheral vascular disease was found to be a significant association in multivariate analysis and history of myocardial infarction trended to be significant.

In our study, we found that a reduced 6-minute walk distance, a measure of overall exercise capacity, incrementally increased the association with VTE. The 6-minute walk test has been found to be a significant prognostic indicator in several cardiopulmonary diseases such as COPD, congestive heart failure, and pulmonary hypertension. ${ }^{21-23}$ Physical inactivity has been associated with an increased risk of VTE in the past. The Nurses' Health Study, following 69,950 female nurses for an average of 18 years, found that those that were the most sedentary were 2 to 3 times more likely to develop an unprovoked VTE compared to those that were the least sedentary. ${ }^{24}$ This association remained significant after controlling for multiple other factors, including age, BMI, and other medical disease. These findings suggest that physical inactivity of any sort, whether due to a sedentary lifestyle or physical limitation, increases risk of VTE. Whether the reduction in 6-minute walk distance in our cohort is due to severity of lung disease or other comorbidities that could reduce exercise capacity (e.g. osteoarthritis, peripheral vascular disease, stroke) is not clear.

The relationship between BMI and the risk of VTE has been well established, in both men and women. The Nurses' Health Study revealed that the risk ratio of $\mathrm{PE}$ in women with a BMI of $29.0 \mathrm{~kg} / \mathrm{m}^{2}$ or greater was 3.2 compared to those with a BMI of $21.0 \mathrm{~kg} / \mathrm{m}^{2}$ or less. ${ }^{25}$ The Study of Men Born in 1913 found that men in the highest decile of waist circumference had an adjusted relative risk of VTE of 3.92 compared to those in the lowest decile. ${ }^{26}$ The National Hospital Discharge Survey showed that obesity conferred a relative risk of 2.18 and 2.50 for PE and deep venous thrombosis, respectively. ${ }^{27}$ Our study supports the association of BMI and VTE risk in COPD individuals with moderate to severe airflow obstruction.

Pneumothorax was another significant covariate in our multivariate model, and there was a trend toward statistical significance for gastroesophageal reflux disease. There is little data on the associations between these comorbidities and VTE in prior literature, and to our knowledge this study is the first to make these associations in the COPD population. A possible mechanism for pneumothorax is the immobility necessary after the insertion of a chest tube and pain with movement limiting activity, leading to lower extremity venous stasis. It is unclear what, if any, mechanism is responsible for the link between gastroesophageal reflux and VTE. Further study is necessary to elucidate an underlying mechanism.

Congestive heart failure has been shown to be a risk factor for VTE in several studies. VTE is common in patients with heart failure, with a prevalence of up to 30 percent. $^{28}$ In an overview of 32 trials including over 7000 patients with heart failure, PE was identified as the fifth most common cause of death. ${ }^{29}$ Several studies have revealed that congestive heart failure confers an increased risk of 2.15-2.93 for VTE. ${ }^{29-31}$

This study has some noteworthy limitations. The assessment of VTE, as well as medical history, was based on patient recollection, which lends to recall bias. There was no confirmation of diagnoses by medical records. The type of VTE (i.e. spontaneous unprovoked, related to a medical event like surgery, or associated with an intravenous catheter), the unknown time period between the event and enrollment, the time course of its occurrence (i.e. during an exacerbation or during a stable state, before or after the diagnosis of other comorbidities), and length or adequacy of treatment could not be assessed. As this was a crosssectional analysis, it is difficult to assess causality of these risk factors for VTE and one can only assess associations, thereby leading to temporal bias. We are unable to assess outcomes for those with a history of VTE. Nonetheless we believe this analysis sheds light on important differences between COPD patients with a history of VTE and those without.

In summary, participants with moderate to severe COPD and VTE are heavier, have a lower exercise capacity, have more evidence of atherosclerotic disease such as peripheral vascular disease and myocardial infarction, and have a greater history of pneumothorax, congestive heart failure, and gastroesophageal reflux disease. This study describes a clinical profile of COPD individuals that are at higher risk for the development of VTE. The clinician should maintain a heightened clinical suspicion for VTE in these patients that present 
with dyspnea and should not assume that COPD exacerbation is the most likely diagnosis. Further study of COPD individuals with clinically confirmed VTE and subsequent comprehensive clinical characterization is needed to solidify risk factors for VTE in this patient population.

\section{Acknowledgements}

Victor Kim is the guarantor of the content of the manuscript, including the data and analysis. All authors have made substantial contributions to conception and design, or acquisition of data, or analysis and interpretation of data, have drafted the submitted article or revised it critically for important intellectual content, have provided final approval of the version to be published, and have agreed to be accountable for all aspects of the work in ensuring that questions related to the accuracy or integrity of any part of the work are appropriately investigated and resolved.

Dr. Kim had full access to all the data in the study and he, as well as the COPDGene Investigators, takes responsibility for the integrity of the data. Dr. Kim takes responsibility for the accuracy of the data analysis.

The authors acknowledge and thank the COPDGene Core Teams:

Administrative Core: JD Crapo (principal investigator), EK Silverman (principal investigator), BJ Make, EA Regan, S Bratschie, R Lantz, S Melanson, L Stepp. Executive Committee: T Beaty, RP Bowler, JD Crapo, JL Curtis, D Everett, MK Han, JE Hokanson, D Lynch, BJ Make, EA Regan, EK Silverman, ER Sutherland. External Advisory Committee: ER Bleecker, HO Coxson, RG Crystal, JC Hogg, MA Province, SI Rennard, DC Thomas. NHLBI: T Croxton, W Gan, L Postow. COPD Foundation: JW Walsh, R Plant, D Prieto. Data Coordinating Center: D Everett, A Williams, R Knowles, C Wilson. Epidemiology Core: J Hokanson, J BlackShinn, G Kinney. Genetic Analysis Core: T Beaty, PJ Castaldi, M Cho, DL DeMeo, MG Foreman, NN Hansel, ME Hardin, C Hersh, J Hetmanski, JE Hokanson, N Laird, C Lange, SM Lutz, M Mattheisen, M McDonald, MM Parker, EA Regan, S Santorico, EK Silverman, ES Wan, J Zhou. Genotyping Cores: Genome-Wide Core: T Beaty. Candidate Genotyping Core: CP Hersh, EK Silverman. Imaging Core: D Lynch, MA Qaisi, J Akhavan, CW Cox, HO Coxson, D Cusick, JG Dy, S Ginsburg, EA Hoffman, PF Judy, A Kluiber, A McKenzie, JD Newell, Jr., JJ Reilly, Jr., J Ross, RSJ Estepar, JD
Schroeder, J Sieren, A Sitek, D Stinson, E van Beek, GR Washko, J Zach. Pulmonary Function Testing Quality Assurance Core: R Jensen, ER Sutherland, Biological Repository, Johns Hopkins University, Baltimore, MD: H Farzadegan, S Bragan, S Cayetano

The authors further wish to acknowledge the COPDGene Investigators from the participating Clinical Centers: Ann Arbor VA Medical Center, MI. J Curtis, E Kazerooni. Baylor College of Medicine, Houston, TX: N Hanania, P Alapat, V Bandi, K Guntupalli, E Guy, A Mallampalli, C Trinh, M Atik, H Al-Azzawi, M Willis, S Pinero, L Fahr, A Nachiappan, C Bray, LA Frigini, C Farinas, D Katz, J Freytes, AM Marciel. Brigham and Women's Hospital, Boston, MA: D DeMeo, C Hersh, G Washko, F Jacobson, H Hatabu, P Clarke, R Gill, A Hunsaker, B TrotmanDickenson, R Madan. Columbia University, New York, NY: RG Barr, B Thomashow, J Austin, B D'Souza. Duke University Medical Center, Durham, NC: N MacIntyre, Jr., L Washington, HP McAdams. Fallon Clinic, Worcester, MA: R Rosiello, T Bresnahan, J Bradley, S Kuong, S Meller, S Roland. Health Partners Research Foundation, Minneapolis, MN: C McEvoy, J Tashjian. Johns Hopkins University, Baltimore, MD: R Wise, N Hansel, R Brown, G Diette, K Horton. Los Angeles Biomedical Research Institute at Harbor University of California-Los Angeles Medical Center: R Casaburi, J Porszasz, H Fischer, M Budoff, M Rambod, ME DeBakey. VA Medical Center, Houston, TX: A Sharafkhaneh, C Trinh, H Kamal, R Darvishi, M Willis, S Pinero, L Fahr, A Nachiappan, C Bray, LA Frigini, C Farinas, D Katz, J Freytes, AM Marciel. Minneapolis VA, MN: D Niewoehner, Q Anderson, K Rice, A Caine. Morehouse School of Medicine, Atlanta, GA: M Foreman, G Westney, E Berkowitz. National Jewish Health, Denver, CO: R Bowler, D Lynch, J Schroeder, V Hale, J Armstrong, II, D Dyer, J Chung, C Cox. Temple University, Philadelphia, PA: G Criner, V Kim, N Marchetti, A Satti, AJ Mamary, R Steiner, C Dass, L Cone. University of Alabama, Birmingham: W Bailey, M Dransfield, M Wells, S Bhatt, $\mathrm{H}$ Nath, S Singh. University of California, San Diego: J Ramsdell, P Friedman. University of Iowa, Iowa City: A Cornellas, J Newell, Jr., EJR van Beek. University of Michigan, Ann Arbor: F Martinez, M Han, E Kazerooni. University of Minnesota, Minneapolis: C Wendt, T Allen. University of Pittsburgh, PA: F Sciurba, J Weissfeld, C Fuhrman, J Bon, D Hooper. University of Texas Health Science Center at San Antonio: A Anzueto, S Adams, C Orozco, M Ruiz, A Mumbower, A Kruger, C Restrepo, M 
Lane.

\section{Declaration of Interest}

VK has participated in clinical trials sponsored by Boehringer Ingelheim, Glaxo-Smith-Kline, Medimmune, and Roche pharmaceuticals. VK is supported by NHLBI K23HL094696-03. NG, JC, HZ, and DEC have nothing to disclose. EKS received grant support and consulting fees from GlaxoSmithKline for studies of COPD genetics. EKS received grant support from GlaxoSmithKline for studies of COPD genetics, and he received honoraria and consulting fees from AstraZeneca, Merck, and GlaxoSmithKline. GJC has served on Advisory Committees for Boehringer Ingelheim, Ikaria, Holaira, CSA and Amirall. All of these sums are less than $\$ 2,500$. GJC has received research grants from: Boehringer Ingelheim, Forest, Actelion, Glaxo-Smith-Kline, AstraZeneca, Pearl, Novartis Pharmaceuticals, Pulmonx, PneumRX and Aeris Therapeutics. All research grant monies are deposited and controlled by Temple University.

The COPDGene project is supported by grant awards R01 HL089856 and R01 HL089897 from the NHLBI. The COPDGene project is also supported by the COPD Foundation through contributions made to an Industry Advisory Board comprised of AstraZeneca, Boehringer Ingelheim, Novartis, Pfizer, Siemens and Sunovion. 


\section{References}

1. Ambrosetti M, Ageno W, Spanevello A, Salerno M, Pedretti RF. Prevalence and prevention of venous thromboembolism in patients with acute exacerbations of COPD. Thromb Res. 2003;112(4):203-207. doi: http://dx.doi.org/10.1016/j. thromres.2003.12.003

2. Baum GL, Fisher FD. The relationship of fatal pulmonary insufficiency with cor pulmonale, right-sided mural thrombi and pulmonary emboli: A preliminary report. Am J Med Sci. 1960;240:609-612.

doi: http://dx.doi.org/10.1097/00000441-196011000-00009

3. Mitchell RS, Silvers GW, Dart GA, et al. Clinical and morphologic correlations in chronic airway obstruction. Aspen Emphysema Conf. 1968;9:109-123.

4. Tillie-Leblond I, Marquette CH, Perez T, et al. Pulmonary embolism in patients with unexplained exacerbation of chronic obstructive pulmonary disease: Prevalence and risk factors. Ann Intern Med. 2006;144(6):390-396. doi: http://dx.doi. org/10.7326/0003-4819-144-6-200603210-00005

5. Akgun M, Meral M, Onbas $\mathrm{O}$, et al. Comparison of clinical characteristics and outcomes of patients with COPD exacerbation with or without venous thromboembolism. Respiration. 2006;73(4):428-433. doi: http://dx.doi.org/10.1159/000092952

6. Erelel M, Cuhadaroglu C, Ece T, Arseven O. The frequency of deep venous thrombosis and pulmonary embolus in acute exacerbation of chronic obstructive pulmonary disease. Respir Med. 2002;96(7):515-518. doi: http://dx.doi.org/10.1053/ rmed.2002.1313

7. Tillie-Leblond I, Mastora I, Radenne F, et al. Risk of pulmonary embolism after a negative spiral CT angiogram in patients with pulmonary disease: 1-year clinical follow-up study. Radiology. 2002; 223(2):461-467.

doi: http://dx.doi.org/10.1148/radiol.2232010913

8. Mispelaere D, Glerant JC, Audebert M, Remond A, SevestrePietri MA, Jounieaux V. Pulmonary embolism and sibilant types of chronic obstructive pulmonary disease decompensations. Rev Mal Respir. 2002; 19(4):415-423.

9. Gunen H, Gulbas G, In E, Yetkin O, Hacievliyagil SS. Venous thromboemboli and exacerbations of COPD. Eur Respir J. 2010;35(6):1243-1248.

doi: http://dx.doi.org/10.1183/09031936.00120909

10. Regan EA, Hokanson JE, Murphy JR, et al. Genetic epidemiology of COPD (COPDGene) study design. COPD. 2010;7(1):32-43. doi: http://dx.doi.org/10.3109/15412550903499522

11. Piazza G, Goldhaber SZ, Kroll A, Goldberg RJ, Emery C, Spencer FA. Venous thromboembolism in patients with chronic obstructive pulmonary disease. Am J Med. 2012;125(10):10101018. doi: http://dx.doi.org/10.1016/j.amjmed.2012.03.007

12. Monreal M, Munoz-Torrero JF, Naraine VS, et al. Pulmonary embolism in patients with chronic obstructive pulmonary disease or congestive heart failure. Am J Med. 2006;119(10):851858. doi: http://dx.doi.org/10.1016/j.amjmed.2005.11.035

13. Rutschmann OT, Cornuz J, Poletti PA, et al. Should pulmonary embolism be suspected in exacerbation of chronic obstructive pulmonary disease? Thorax. 2007;62(2):121-125. dio: http://dx.doi.org/10.1136/thx.2006.065557
14. Rizkallah J, Man SF, Sin DD. Prevalence of pulmonary embolism in acute exacerbations of COPD: A systematic review and metaanalysis. Chest. 2009;135(3):786-793.

doi: http://dx.doi.org/10.1378/chest.08-1516

15. Duan SC, Yang YH, Li XY, et al. Prevalence of deep venous thrombosis in patients with acute exacerbation of chronic obstructive pulmonary disease. Chin Med J (Article in English). 2010;123(12):1510-1514.

16. Winter JH, Buckler PW, Bautista AP, et al. Frequency of venous thrombosis in patients with an exacerbation of chronic obstructive lung disease. Thorax. 1983;38(8):605-608. doi: http:// dx.doi.org/10.1136/thx.38.8.605

17. Prandoni P, Bilora F, Marchiori A, et al. An association between atherosclerosis and venous thrombosis. N Engl J Med. 2003 10;348(15):1435-1441.

18. Deguchi H, Pecheniuk NM, Elias DJ, Averell PM, Griffin JH. High-density lipoprotein deficiency and dyslipoproteinemia associated with venous thrombosis in men. Circulation. 2005;112(6):893-899. doi: http://dx.doi.org/10.1161/CIRCULATIONAHA.104.521344

19. Ageno W, Prandoni P, Romualdi E, et al. The metabolic syndrome and the risk of venous thrombosis: A case-control study. J Thromb Haemost. 2006;4(9):1914-1918.

doi: http://dx.doi.org/10.1111/j.1538-7836.2006.02132.x

20. Sorensen HT, Horvath-Puho E, Pedersen L, Baron JA, Prandoni P. Venous thromboembolism and subsequent hospitalisation due to acute arterial cardiovascular events: A 20-year cohort study. Lancet. 2007; 370(9601):1773-1779. doi: http://dx.doi.org/10.1016/S0140-6736(07)61745-0

21. Badesch DB, Champion HC, Sanchez MA, et al. Diagnosis and assessment of pulmonary arterial hypertension. J Am Coll Cardiol. 2009;54(1 Suppl):S55-66. doi: http://dx.doi.org/10.1016/j. jacc.2009.04.011

22. Shah MR, Hasselblad V, Gheorghiade M, et al. Prognostic usefulness of the six-minute walk in patients with advanced congestive heart failure secondary to ischemic or nonischemic cardiomyopathy. Am J Cardiol. 2001;88(9):987-993. doi: http://dx.doi.org/10.1016/S0002-9149(01)01975-0

23. Celli BR, Cote CG, Marin JM, et al. The body-mass index, airflow obstruction, dyspnea, and exercise capacity index in chronic obstructive pulmonary disease. N Engl J Med. 2004;350(10):10051012. doi: http://dx.doi.org/10.1056/NEJMoa021322

24. Kabrhel C, Varraso R, Goldhaber SZ, Rimm E, Camargo CA Jr. Physical inactivity and idiopathic pulmonary embolism in women: Prospective study. BMJ. 2011;343:d3867. doi: http://dx.doi.org/10.1136/bmj.d3867

25. Goldhaber SZ, Grodstein F, Stampfer MJ, et al. A prospective study of risk factors for pulmonary embolism in women. JAMA. 1997;277(8):642-645. doi: http://dx.doi.org/10.1001/jama.1997.03540320044033

26. Hansson PO, Eriksson H, Welin L, Svardsudd K, Wilhelmsen L. Smoking and abdominal obesity: Risk factors for venous thromboembolism among middle-aged men: The study of men born in 1913. Arch Intern Med. 1999;159(16):1886-1890. doi: http://dx.doi.org/10.1001/archinte.159.16.1886 
27. Stein PD, Beemath A, Olson RE. Obesity as a risk factor in venous thromboembolism. Am J Med. 2005;118(9):978-980. doi: http://dx.doi.org/10.1016/j.amjmed.2005.03.012

28. Pesavento R, Piovella C, Prandoni P. Heart disease in patients with pulmonary embolism. Curr Opin Pulm Med. 2010;16(5):415418. doi: http://dx.doi.org/10.1097/MCP.0b013e32833b6581

29. Garg R, Yusuf S. Overview of randomized trials of angiotensinconverting enzyme inhibitors on mortality and morbidity in patients with heart failure. Collaborative group on ACE inhibitor trials. JAMA. 1995;273(18):1450-1456.

doi: http://dx.doi.org/10.1001/jama.1995.03520420066040

30. Samama MM. An epidemiologic study of risk factors for deep vein thrombosis in medical outpatients: The sirius study. Arch Intern Med. 2000;160(22):3415-3420. doi: http://dx.doi. org/10.1001/archinte.160.22.3415

31. Howell MD, Geraci JM, Knowlton AA. Congestive heart failure and outpatient risk of venous thromboembolism: A retrospective, case-control study. J Clin Epidemiol. 2001;54(8):810-816. doi: http://dx.doi.org/10.1016/S0895-4356(00)00373-5 